\title{
Timpanismo bilateral de bolsa gutural em potro
}

\author{
Bilateral tympany of a guttural pouch in foal \\ Carlos Augusto Araújo Valadão ${ }^{1}$ Júlio Carlos Canola ${ }^{2}$ \\ Roberta Ferro de Godoy ${ }^{3}$
}

\begin{abstract}
Uma potra da raça Quarto de Milha com dois meses de idade apresentava aumento de volume bilateral na região da parótida desde algumas horas após o nascimento. Por exame radiográfico diagnosticou-se timpanismo bilateral de bolsa gutural. Realizou-se a abertura cirúrgica da bolsa gutural esquerda e fenestrou-se o septo medial das bolsas guturais. Adicionalmente, procedeu-se à ressecção parcial da mucosa na abertura do orifício guturo-faríngeo. A afecção foi debelada, sem recidivas.
\end{abstract}

Palavras-chave: bolsa gutural, timpanismo, potro.

\section{ABSTRACT}

A 2-month old Quarter Horse filly presented, since few hours after birth, increased bilateral volume in the parotid gland region, with progressive enlargement. The radiographic examination revealed bilateral tympany of guttural pouch. Surgery was performed by medial septal fenestration. In addition, partial ressection of mucous membrane of the pharingeal orifice was performed. The disease was healed without recurrences.

Key words: guttural pouch, tympany, foal.

As bolsas guturais são divertículos da tuba auditiva, delimitadas dorsalmente pelo atlas e cranioventralmente pela faringe, com a qual se comunica através do orifício guturo-faríngeo, que possui $2,5 \mathrm{~cm}$ de diâmetro. As paredes das bolsas guturais são sobrepostas e formam o septo medial (MILNE; FESSLER, 1972; FREEMAN, 1992).

Dentre as afecções da bolsa gutural, o timpanismo é a menos freqüente (WALSH; WEINBERG, 1979; McCUE et al., 1989). O timpanismo unilateral e, mais raramente, bilateral parece ser mais comum em fêmeas do que em machos e em animais jovens (McCUE et al., 1989; FREEMAN, 1992). A etiologia do timpanismo bilateral da bolsa gutural é desconhecida, podendo ser causado por um defeito no orifício guturo-faríngeo, pregueamento da mucosa, espessamento da borda lateral do orifício guturofaríngeo, inflamação ou disfunção muscular. Nestes casos, o orifício guturo-faríngeo atuaria como uma válvula unidirecional, permitindo que o ar adentre na bolsa gutural, mas impedindo que ele saia (FORBES; BENNELL, 1975; FREEMAN, 1992). No caso de má formação congênita, há um espessamento ou outro tipo de alteração da borda lateral do orifício guturofaríngeo, aprisionando ar e fluidos na bolsa gutural (FORBES; BENNELL, 1975; McCUE et al., 1989).

Um aumento de volume flutuante, não inflamatório, indolor e complacente, na região da parótida, associado ou não com dispnéia, é o principal sinal clínico do timpanismo de bolsa gutural (MILNE; FESSLER, 1972; FREEMAN, 1992).

O timpanismo de bolsa gutural pode não interferir no desenvolvimento e crescimento do animal,

\footnotetext{
${ }^{1}$ Médico Veterinário, Professor Adjunto, Departamento de Clínica e Cirurgia veterinária (DCCV), Faculdade de Ciências Agrárias e Veterinárias (FCAV), UNESP, Jaboticabal, 14884-900, Jaboticabal, SP. E-mail: valadao@ fcav.unesp.br. Autor para correspondência. ${ }^{2}$ Médico Veterinário, Professor Assistente Doutor, DCCV, FCAV, UNESP, Jaboticabal.

${ }^{3}$ Médico Veterinário, Pós-graduando do Curso de Mestrado em Cirurgia Veterinária, FCAV, UNESP, Jaboticabal.
} 
mas há casos em que ocorre dispnéia, disfagia, pneumonia por aspiração e, não raramente, empiema de bolsa gutural secundário (FREEMAN, 1992; EDWARDS; SANTSCHI, 2002). Segundo FREEMAN (1992), o empiema e a pneumonia secundários evoluem favoravelmente após o tratamento do timpanismo. $\mathrm{O}$ diagnóstico é confirmado por exame físico, endoscopia e radiografia (EDWARDS; SANTSCHI, 2002).

O tratamento clínico inclui antibióticos e antiinflamatórios, pouco efetivos nos casos de timpanismo de bolsa gutural. Como tratamento cirúrgico recomenda-se que a bolsa gutural afetada seja abordada através do triângulo de Viborg ou pela técnica de Whitehouse modificada. Após a abertura cirúrgica, retira-se um segmento $(1,5 \times 2,5 \mathrm{~cm})$ da prega da mucosa da lâmina medial da tuba auditiva para aumentar o orifício guturo-faríngeo. Em outra técnica, o septo medial é fenestrado removendo-se um segmento de dois centímetros, para que o ar aprisionado na bolsa gutural obstruída passe para o lado oposto e seja eliminado, na faringe. Quando o envolvimento é bilateral ou a distinção entre a uni ou bilateralidade da afecção é difícil, os dois procedimentos devem ser combinados. O prognóstico de animais portadores de timpanismo de bolsa gutural é bom, principalmente se a afecção é unilateral e se tratada nos estágios iniciais (FREEMAN, 1992; EDWARDS \& SANTSCHI, 2002).

Uma potra da raça Quarto de Milha, de dois meses de idade, com $110 \mathrm{~kg}$ de peso corpóreo, que, algumas horas após o nascimento, apresentou aumento de volume bilateral progressivo na região parotídea, foi encaminhada ao Hospital Veterinário da FCAV-Unesp, Jaboticabal, S.P.

Ao exame clínico, notou-se aumento de volume bilateral, simétrico, indolor, macio e flutuante (Figura 1a), sem aumento de temperatura local, na região parotídea. $\mathrm{O}$ volume diminuía de tamanho quando pressionado progressivamente, mas voltava ao tamanho original, após a manipulação, em um curto intervalo de tempo, com a movimentação respiratória do paciente. À auscultação pulmonar verificou-se estertores bilaterais discretos, sem dispnéia. $\mathrm{O}$ animal encontrava-se alerta e com bom desenvolvimento corporal. Projeções radiográficas látero-lateral e ventro dorsal da cabeça e região cervical do animal foram feitas com penetrações equivalentes a $56 \mathrm{KVp} \mathrm{e} 0,05 \mathrm{~ms}$. A distensão bilateral por ar nas bolsas guturais atingia a epífise distal da segunda vértebra cervical (C2) (Figura 1b), permitiu o diagnóstico de timpanismo bilateral de bolsa gutural. A cavidade torácica foi examinada radiograficamente, avaliando-se a densidade pulmonar, quando foi constatada a presença de um padrão pulmonar misto, constituída pelos tipos intersticial e bronquial, com pneumonia secundária.

Diagnosticada a afecção, o animal foi encaminhado para o tratamento cirúrgico. A potra foi pré-anestesiada com $0,2 \mathrm{mg} \mathrm{kg}^{-1}$, IM, de midazolan (Dormium $\AA$ ) e $0,6 \mathrm{mg} \mathrm{kg}^{-1}$, IV, de xilazina (Virbaxyl 2\%®) após 10 minutos. Cinco minutos depois procedeu-se a indução com cetamina (Francotar®) na dose de $2 \mathrm{mg}$ $\mathrm{kg}^{-1}$, IV. Após a intubação oro-traqueal com sonda de Magill $\mathrm{n}^{\circ} 18$, o animal foi posicionado em decúbito lateral direito e mantido sob anestesia inalatória com halotano (Halothano®) a $3 \%$ em oxigênio puro, utilizando-se um circuito anestésico semifechado.

Após tricotomia e preparo do campo operatório, uma pipeta de Chamber foi introduzida pelo meato nasal ventral direito, passando pelo orifício guturo-faríngeo até alcançar a bolsa gutural direita. Realizou-se uma incisão na pele de, aproximadamente, seis centímetros, na região esquerda, ventral à veia maxilar externa (triângulo de Viborg), sobre a área mais proeminente do aumento de volume.

A fascia subcutânea foi divulsionada até a visibilização da parede lateral da bolsa gutural esquerda (Figura 1c). Seqüencialmente, incidiu-se a parede e explorou-se a cavidade gutural, não sendo detectada a presença de fluidos. Assim, logo após ter sido determinada a localização do septo medial, pelo pressionamento as pipeta de Chamber (Figura 1d), posicionada na bolsa gutural direita, procedeu-se à fenestração do septo medial, com ressecção de um segmento deste correspondente à área de, aproximadamente, três centímetros de diâmetro, criando, assim uma abertura permanente, a fim de permitir o fluxo de ar entre as bolsas guturais (Figura $1 \mathrm{e})$.

Posteriormente, tracionou-se, com uma pinça Allis, a borda medial da mucosa do orifício guturo-faríngeo esquerdo, ressecando-se com tesoura de Mayo curva-romba, um segmento de mucosa de aproximadamente $1 \mathrm{~cm}^{2}$ com o objetivo de restabelecer a drenagem do ar pelo orifício. Repetiu-se o mesmo procedimento para o lado direito.

Passou-se uma sonda de Levine, número 22, pelo orifício guturo-faríngeo direito e sua extremidade foi passada pela fenestração para a bolsa gutural esquerda e introduzida no orifício guturofaríngeo esquerdo, até sair pela narina correspondente para, posteriormente, ser unida à outra extremidade passada pelo lado direito. A parede da bolsa gutural foi suturada empregando-se padrão simples contínuo com categute cromado 2-0 (Cromado 2-0®). Foi realizada a aproximação do tecido subcutâneo com padrão Cushing com categute cromado 0 (Cromado 


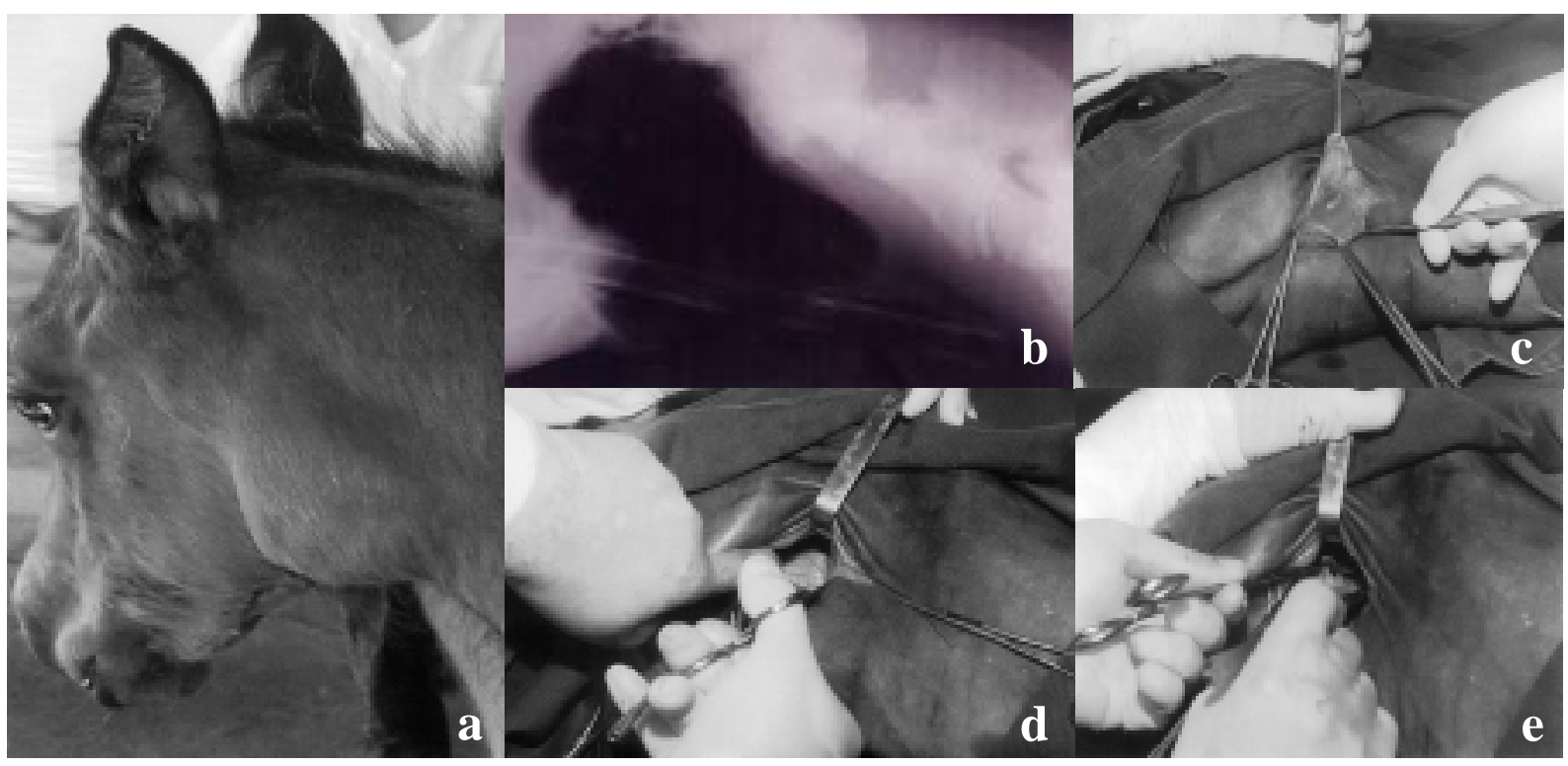

Figura 1 - Apresentação clínica do timpanismo bilateral de bolsa gutural, mostrando o aumento de volume na região da parótida (a); Imagem radiográfica das bolsas guturais, onde se observa a distensão por ar. Os recessos caudais das bolsas guturais relacionavam a epífise distal da segunda vértebra cervical (b); Procedimento cirúrgico realizado, mostrando o acesso à bolsa gutural esquerda, pelo triângulo de Viborg (c); Fotografia durante o processo cirúrgico, mostrando a identificação do septo medial da bolsa gutural (d); Fotografia durante o procedimento cirúrgico, mostrando a fenestração do septo medial da bolsa gutural (e).

$0 ®)$ e a sutura da pele foi praticada com supramid 2 (Suturamid®), em pontos simples separados.

Durante o período pós-operatório, foi realizada antibioticoterapia com $2 \mathrm{mg} \mathrm{kg}^{-1}, \mathrm{IV}$, de ceftiofur (Minoxel®), duas vezes ao dia, durante cinco dias, e curativo local diário com iodo povidine. A sonda foi retirada três dias após a cirurgia e a sutura de pele após dez dias.

Não foi observada recidiva do aumento de volume e, decorridos dez dias da cirurgia, realizou-se exame radiográfico das bolsas guturais, que se mostravam de tamanho normal.

A fenestração do septo medial das bolsas guturais é o método mais recomendado para corrigir o timpanismo unilateral (McCUE et al., 1989), sendo menos eficiente no caso de afecção bilateral (FORBES; BENNELL, 1975). A retirada do fragmento de mucosa no orifício guturo-faríngeo pode ser adotada isoladamente, porém existem relatos de recidivas tanto para a fenestração isolada $(33 \%)$ como para a fenestração combinada com a abertura do orifício guturo-faríngeo (29\%) (McCUE et al., 1989). No caso apresentado, obteve-se sucesso associando-se a fenestração com a ressecção do fragmento de mucosa no orifício guturo-faríngeo.
A recuperação do animal foi satisfatória e, decorridos 10 meses da intervenção, não foram observadas complicações. Houve remissão da pneumonia secundária observada no exame radiográfico.

\section{REFERÊNCIAS BIBLIOGRÁFICAS}

EDWARDS, R.B.; SANTSCHI, E.M. Diagnosis and treatment of upper airway disorders in the foal. In: ANNUAL VETERINARY SYMPOSIUM ACVS (AMERICAN COLLEGE OF VETERINARY SURGEONS), 12., 2002, San Diego, EUA. Proceedings... Betheseda : American College of Veterinary Surgeons, 2002. p.213-216.

FORBES, J.R.S.; BENNELL, D.G. Tympany of the gutteral pouch in a foal. Australian Vet J, v.51, p.164, 1975.

FREEMAN, D.E. Guttural pouch. In: AUER, J.A. Equine surgery. Philadelphia: Saunders, 1992. p.481-482.

McCUE, P.M.; FREEMAN, D.E.; DONAWICK, W.J. Guttural pouch tympany: 15 cases (1977-1986). J Am Vet Med Assoc, v.194, n.12, p.1761-1763, 1989.

MILNE, W.N.; FESSLER, J.F. Tympanites of the guttural pouch in a foal. J Am Vet Med Assoc, v.161, n.1, p.61-64, 1972.

WALSH, J.M.; WEINBERG, H. Tympanites of the guttural pouch in a foal. Vet Med, v.2, p.204-205, 1979. 